occurred at Minneapolis in 1878. Professors Peck and Peck ham of the University of Minnesota conducted experimental work in the investigation which followed the explosion. In this investigation it was found that by blowing $2 \mathrm{oz}$. of dust upon an open flame in a box containing $2 \mathrm{cu}$. ft. of air sufficient pressure was developed to lift two men standing on the cover. $^{9}$ This would mean diffusion at the rate of $1 \mathrm{oz}$. of dust to $1 \mathrm{cu}$. $\mathrm{ft}$. of air space. Their report states that a sack of flour and 4,000 cu. ft. of air will generate force enough to throw 2,500 tons $100 \mathrm{ft}$. high.

The Bureau of Mines reports that explosions could be produced when only $0.032 \mathrm{oz}$. of coal dust was suspended in $1 \mathrm{cu}$ $\mathrm{ft}$. of air, or $1 \mathrm{lb}$. in $500 \mathrm{cu}$. ft. It was found in order to produce complete combustion all the oxygen in $1 \mathrm{cr}$. $\mathrm{ft}$. of air was required to burn $0.123 \mathrm{oz}$. of the dust used.

In the French experiments conducted by Taffanel an instance is cited in which the low weight of $0.023 \mathrm{oz}$. of dust per cu. ft. of space was sufficient to produce an ignition.

Experimental work is now in progress to determine definitely the smallest amount of dust in suspension per unit area through which an explosion can propagate.

\section{RELATION OF HUMIDITY TO EXPLOSION FREQUENCY}

The relation of humidity to the frequency of dust explosions has been markedly noticeable in the investigational work. This is especially true in connection with explosions where static electricity has appeared as a probable cause. In the large number of thresher explosions in the Pacific Northwest, which comprises the inter-mountain territory between the Cascade and Rocky Mountain ranges, it was found that in 128 cases 86 explosions, or 70 per cent of the total, occurred between the hours of 1 and 7 P. M., when the humidity was extremely low. The range of humidity was usually from 6 to 17 per cent. These explosions have occurred in grain separators during the threshing of wheat containing smut dust. In 112 explosions from 1 to 35 per cent of the heads of wheat being threshed were smutted. In 108 cases the average smut percentage was 15 .

\section{WIND POWER*}

ON behalf of the Zionist Organization, Dr. Ing. M. Mayersohn has recently studied the wind-power problem with special regard to installations in Palestine. In his dissertation, presented to the Berlin Technical High School, he has collected a great deal of useful information on the types of wind mills used in Denmark, Germany and Holland, on experience gained with them and on the design of new installations. He makes out a better case for windmills than might be expected. $\mathrm{He}$ gives information on 477 installations-not ordinary grain mills. Of the 415 German mills of those tables 87 per cent had worked very satisfactorily for periods of up to eighteen years. In Denmark, the utilization of wind power has been much stimulated during the war; in several instances small communities are coöperating in supplying the local electricity works with from 20 per cent to 50 per cent of the power needed.

The favorite new wind motors for this purpose are Agricco motors, made by the firm of Hans L. Larsen, and known hence also as the Hansell motors. The Agricco wheel consists of five wings of the propeller type, made of sheet-iron, each wing turning against the action of a spring about its radial arm, to the one side of which it is attached. The older types common in Denmark are the Paul La Cour wheel-four or six arms set cross-ways with vanes of the Venetian-blind typeand the Sörensen cone motor. The six wings of this latter motor would, if placed together, make up the surface of a cone of a very obtuse apex angle; each wing is built up of curved cross-vanes. Sörensen motors have been built up to 27 m. (88 ft.) in diameter for $50 \mathrm{hp}$., but they are not so efficient as the Agricco. I'he old-fashioned wind roses, large

\footnotetext{
${ }^{9}$ Chemical Engineer, March, April, May, 1908.

*From Engineering, (London) Dec. 10, 1920, p. 769
}

wheels consisting of many radial vanes of wood, are still built in Denmark; most of the vanes we have mentioned are made of galvanized iron. More common in general are the wind turbines of the American construction, up to $5 \mathrm{~m}$. in diameter, and the German wind turbines of the Herkules type, made in diameters of $15 \mathrm{~m}$. (50 ft.) and even $30 \mathrm{~m}$.

Some of the 477 windmills which Mayersohn inspected or about which he inquired had done thirty-five years' duty. La Cour's Askov mill works still after twenty-three years without having ever been repaired. Only six total wrecks were reported. Repairs are not infrequent, especially in some parts of Germany, where the peasants take the notice too literally that the mills require little attendance. Grease was, moreover, very scarce during the war. Trouble had also arisen because the man in charge, finding that the mill could deal with heavy loads, increased the load until the wheel could not turn and became a prey to the wind. In other cases the wheel would not come to rest, causing overflow and other disturbances. Most of the plants serve for pumping, irrigation or drainage; a few mills drive workshops directly, or propel electric machinery with or without accumulator batteries.

Small agricultural machinery can generally be fitted for wind power, without difficulty. For installations of more than moderate dimensions, however, the project should be studied as carefully as with water power. A wind velocity of $2 \mathrm{~m}$. per second, which can generally be relied upon in Northern Central Europe, is sufficient to start some types of wheels, though the La Cour wheels require speeds of $5 \mathrm{~m}$. But the designer has to inquire into the maxima and minima as well as into the average values. A calm of a day or two is a serious feature; longer calm periods during windy days are also to be reckoned with, and in recognition of the utility of wind power the German Meteorological Office has recently supplemented its reports so that the wind velocity can be traced through its diurnal period. Where calm days must be allowed for, the storage capacity of the plant has to be increased. At Haifa, on the coast of Northern Palestine, a good wind is blowing all the summer months, from May to October, but there are calm days in these two months, when the season changes and when irrigation is still necessary. The meteorological observations taken by the German settlers there before the war show that in 1908 there was no wind on May 17 and 18, and again on May 20 and 21, and on May 26 and May 29. To meet this trouble it is recommended that the storage capacity should be increased from two days to at least three days.

\section{DIRECT CURRENT CONVERSION}

In the French press there appeared a description of an apparatus whose object is the simplification of methods whereby direct current can be converted from one voltage to another. It is manufactured by the Société Romain Bon of Liége and is briefly described by Electrician (London), as follows:

It consists of what is essentially a direct current generator, but with a fixed armature and a rotating field. Instead, however, of the usual arrangement of armature windings, what are in effect a number of series transformers are used, the terminals of which are connected to a commutator from which current can be collected by a system of revolving brushes. This arrangement in combination with the revolving field and an elliptical air gap gives an equipment whereby any desired conversion can be realized by increasing or decreasing the number of ampere turns in the stationary coils. The makers point out that as the general conditions resemble those of a static transformer a minimum of iron and copper are required, and that there are no crossing leads at different potentials, thus facilitating insulation and reducing the risk of short circuit. Commutation is said to present no difficulty, though the usual design is modified by replacing the parallel bars with an arrangement of staggered contacts. Nevertheless, as the biggest machine that has so far been built is $1 \mathrm{kw}$., it is too early to be definite on this point. 


\title{
Thermal Conductivity of Building Materials ${ }^{*}$
}

\author{
Experiments Undertaken to Determine the Heat Losses of Various Structures
}

\section{By C. Schroeder}

$\mathrm{T}$ HE question of conservation of heat in a building pre sents far møre difficulties than søme other prøblems of construction. Usually persons consilering this subject content themselves with the somewhat vague declaration that insulating of "warm" walls shoul be employed. An opinion which rests rather upon the sense of feeling an upon "noncontrollable" experience than upon exact experimental investigations, but the question is undoubtedly of peculiar an pressing importance tolay because of the scarcity an dearness of fuel. Obviously the more pervious to heat a wall is the greater the waste of fuel when the space enclesed by it is to be kept at a bygienic iegree of temperature. ... It is not until comparatively recent jears that an effort has been male to determine these questions by scientific methous. Some time before the beginning of the Great War a start was male in this matter by the Laboratory for Technical Physics connected with the Technical High Schol in Munich. Assistance was lent by the cooperation of the Munich "Institute for the Stualy -f the Economics of Heat," which was founded by industrial circles in October, 191s.

The investigations male by these bodies were based upon the following well-known facts. A source of heat of a constant strength (a støve, raliatør, etc.) was used. $8 y$ means of this

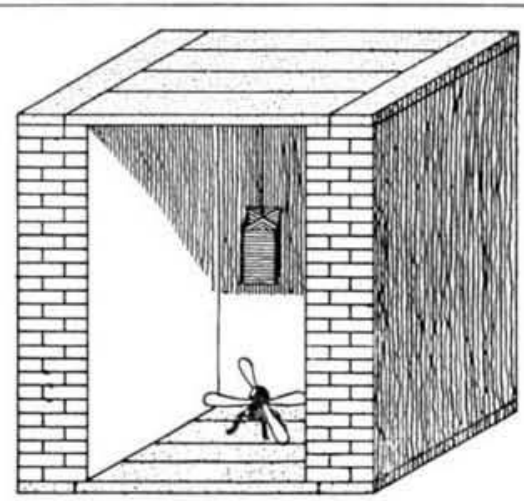

FIG. 1. EXPERIMENTAL CONTAGE FOR TESTING THE CONDUCTIVITY OF HEAT IN BULDING MATERIALS The hot air from the electric heater is distributed evenly by the electric fan

source of heat the air in the røm is first warm an then the walls which enclose the room become heated an finally a portion of the heat which has pentrated the walls passes out int the surrounding atmesphere. There finally eccurs a state of equilibrium in this precess, which can be recognized by the fact that when this state is reached the same amount of heat is given off by the wall int the outer air as has been received by the inner sile of the wall. ... This passage of heat through the wall is comparable to the fowing of a fiuid. The -bstacles met by a stream of water can be overcome only when a certain amount of pressure or a corresponding difference in height is present, an such obstacles may be compared the resistances (which vary accorling to the material) encountered by the current of heat and which the latter can overcome only by a change of temperature corresponding to the resistant object in question. Just as the water can fiow more rapidly over a smoth surface so the denser the body to be penetrated the less resistance encountered by the current of heat; just as a gutter with uneven and rough walls hinders the fow of water, a loose, light, air filled material checlas the fow of the current of heat.

-Translated for the Scientific American Monthiy from Die Umshau (Frankfurt), October 16, 1920.
In analogy to the laws of fluid bodies it is found that within like intervals of time the amount of the heat transmitted increases in the same rati as the area of the surface and as the difference of temperature between the tw sides of the wall, while it lecreases, on the contrary, in proportion to the thickness of the wall; finally, it is in harmony with a special factor, namely, the aegree of conuctivity of heat for the given material. This magnitude, known as the thermal conuctivity number, gives the units of heat which pass through the surface unit of the wall $(1$ sq. $m$.) in the unit of time ( 1 hour) when there is a difference of $1^{\circ} \mathrm{C}$. between the tw surfaces of a wall 1 meter thick.

These thermal conductivity figures have been determined by careful experiments with various building an insulating materials, such as common tile or brick, as alsø the porøus

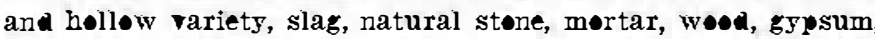
sheets of cork, an of peat fiber, etc. These materials were preparea in sheets having a surface extent of about $1 / 4$ of a seuare meter an were warmed on one side by expesure to an electric source of heat. Special care was taken to have all the heat produced pass through the material to be tested. The thermal conductivity figure was then determined after the stage of permanency was attained, by a calculation in rolving the factors of the given amount of heat, the surface and the thickness of the material. These figures having been -btained it is easy to calculate the quantity of heat transmitted through any given wall composed of one or more of these substances. For example, the following figures were obtained for various walls:

1.44 cal. in a brick wall of a thickness of 1 信 bricks (this may be regarded as the normal wall for awelling houses) ;

$1.66 \mathrm{cal}$. in a gravel cement wall, $40 \mathrm{~m}$. thick;

1.87 cal. in a limestone wall, $1 \frac{1}{2}$ stones thick;

$2.4 \mathrm{cal}$. in a wall $50 \mathrm{~cm}$. thick built of quarry stones.

On the other hand a wall male of hollow tiles, one brick thick gave the figures 1.3 calories, while still more alvan tageous was a well plasterea wall only 1 brick thick of Rhenish porous stone in which the loss of heat was reduced

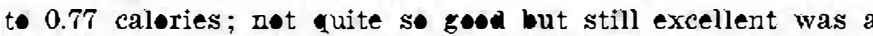
wall of the same thickness male of furnace slag which allowed the passage of about 1.15 calories.

The higher prices and scarcity of building materials have naturally led to inferior construction with a corresponding increase in the amount of heat transmitted through these porer and thinner walls. This can be partly compensated, however, by the use of special insulating materials, such as sheets of cork, peat fiber, etc. It has bees proven in fact, that this distribution of solidity an insulation among twe different materials give especially gow results. Thus we fin that the loss of heat in a brick wall covered with a layer -f insulating material $3 \mathrm{~cm}$. thick reauces the loss of heat as follows :

From 1.44 to 0.78 calories in a wall $11 / 2$ bricks thick

Fr॰m 2.10 to 0.92 caløries in a wall 1 brick thick

Fr॰m 3.85 to 1.17 calories in a wall 1/2 brick thick

A great many new methods of bulding have sprung us since the war; these mostly employ gravel cement or slag cement in combination with layers of air or hollow spaces filled with some insulating material; it is impessible to as sign fixed values to the heat loss in such cases, since the thermal conductivity of cement varies greatly according to its composition, methol of mixture, an density. The heat loss of a structure built with walls consisting of a $6 \mathrm{~cm}$. gravel cement layer, a $12 \mathrm{~cm}$. layer of air, and a $6 \mathrm{~m}$. layer of slag cement is estimate at approximately 2 calories, but when the air space is filled with slag this value is reduced in 
the case of a brick wall $38 \mathrm{~cm}$. thick. Prepared cement blecks which are frequently divided by air layers show a heat lows of 1.2 calories in the most favorable cases. Houses made of wood, or of wood combined with unburnt brick or slag blocks when they contain well distributed air spaces, vary in their heat law from 1.1 to 16 calories.

Testing Heat-loss in Experimental Houses.-F•r the purpose of testing heat-loss in such forms of construction under conditions approximating those encountered in actual practice, small experimental houses were built with side walls, 2 s. meters in area (Fig. 1). These were set up in a large laboratory in order to avoid difficulties and complications due to variations in the weather outdoors. Definite forms of structure was chosen for the walls: A brick wall $11 / 2$ brick thick, a concrete wall composed of gravel cement and slag cement, wooden walls and roofs; the floors and ceilings were constructed of an insulating material having a known thermal conductivity. The source of the heat-an electrically heated body, was placed inside each of these little houses near a fan whose purpose was to distribute the heated air evenly. The method of measuring the loss of heat was the same as in the first experiment. In this manner it was possible to make an immediate measurement of the amount of heat transmitted

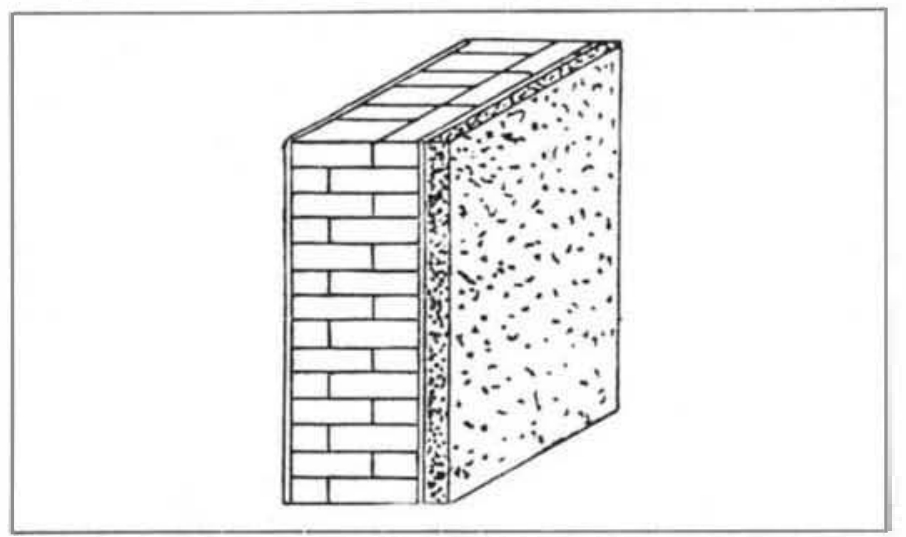

FIG. 2. WALL SH@WING AUXILIARY WALL $\bullet$ F KNOWN THERMAL CONDUCTIVITY IN FRENT $\bullet$ F IT

The heat loss in the wall being tested is found by measuring the temperature on each side of the two walls

through the wall under test. It was also possible to determine the effects preduced by outside influences such as the amount and distribution of humidity, etc. 'The results obtained agreed admirably with the individual values previously secured. 'Thus, for example, the heaf-loss from the brick wall $1 \frac{1}{2}$ bricks thick was found to be 1.43 calories. (Figures simllar to those obtained by theoretical calculation.) A framework structure which was lined with boards on both sides underlaid by plaster covered boards proved excellent, with a lass of only $\$ .8$ calories; without the underlay of plaster covered boards the heat low amounted to 1.2 calories In a swucture composed of hollow cement blocks there was a heat loss of 2.1 calories which indicates that this form of building is of doubtful value.

In order to complete the experiments by a study of the influence exerted by location and climate a simple experiment was devised by means of which the conditions of the heat conductivity in the finished building can be tested in any given instance. As shown in Fig. 2, this method consist in placing in front of the wall to be tested an extra wall having a known thermal conductivity. The room is then heated by any desired source of heat and kept at as even a temperature as possible. The warmth thus produced must pasw through the auxiliary wall before reaching the wall of the room. In each of the two walls a current resistance makes its appearance and, as explained, in the earlier portion of this article, this resistance can be overcome in the case of a given amount of heat only by a given difference of temperature. Consequently, the resistances exhibited to the flow of the heat correspond to the differences of temperature. Since the re sistance to heat conduction of the auriliary wall is a known quantity, it is only necessary to find the temperatures upor each side of the auxiliary wall and each side of the wall to be tested, in order to discover the amount of resistance to the conduction of heat exhibited by the latter. A simple calculation enables us to determine the quantity of heat loss from the amount of resistance displayed.

The present conditions obtaining in Germany as to supplies of coal . . . indicate the great economic importance of this question. It is to be hoped consequently that the Department of Buildings and Construction which has hitherto been cencerned chiefly with the safety from fire and the solidity of buildings, will require that proper care be taken to secure the proper amount of protection against heat loss in their censtruction. In their own interest persons erecting building: should demand of their architects the greatest attention to the securing of economy of fuel, while architects themselves must be advised of the necessity of enlarging their scientific equipment for the practice of their profession by a study of the technology of economy of heat.

RESEARCH IN WOOD FOR THE BUILDING INDUSTRY

For generations the proper size of timbers to use in wood buildings was a matter of custom. Now higher working stresses are permitted by building coles and it is possible to design more economical buildings. This is the result of increasing knowledge of the strength properties of woed. Much of the credit for making available this essential information belongs to the Forest Products Laboratory at Madison, Wisconsin. Considering its relatively meager appropriations from year to year and the financial uncertainties under which it labors, its accomplishments have been great. But the needs of further knowledge in the use of structural timbers are almost unlimited.

How shall built-up beams and columns be designed, and what are these conditions under which their use is desirable? How can structural timbers be preserved from decay and the attacks of borers? What influence have defects on the strength of columns? What stresses should be used in woed girders and trusses of 50 to 70 foot span such as are used in garages? What do we know of the strength of fastenings and joints? Has freproofing and slow-burning construction been fully developed? What of shrinkage and the better seasoning of wood? And with carefully worked out grading rules and consequent higher working stresses why cannot the cost of wood buildings be materially reduced? The Forest Products Laboratory is seeking to solve some of these problems, but in order to de so, it needs the support of industries which will benefit by its results.

\section{DISINTEGRATION OF ROOFING TILE}

Accorm nNG to J. Scott, who writes in the British Clay Worker, 29, 138-140 (1920), roofing tile sometimes disintegrates owing to a fungous growth, a type known as mucer racemose being especially destructive. Rain and dust settle in the pores of the tile and this becomes a foundation for the spores. A net work running through the pores of the vile is formed as the spores grow and in a few days thread-like spore-bearing stalk are sent up and these soon scatter a new lot of spores. The fungus obtains its food partly from the dust and partly fom the tile and the stalks are hollow and filled with a sap traveling upward. The points of these stallw or threads yield ferments which enable them to soften and split off small particles from the tile. During the process volatile mineral matter required for the fungus is drawn from the tile leaving it more susceptible to the destructive action of thawing and freezing. Thus this natural chemical precess proceds, although slowly. Lichen, which very often covers reofing tile, is not destructive to it since it obtains it nourishment mom the air. 